\title{
PENGARUH MODEL PROJECT CITIZEN DALAM PEMBELAJARAN PENDIDIKAN PANCASILA DAN KEWARGANEGARAAN TERHADAP PENGEMBANGAN CIVIC COMPETENCES PESERTA DIDIK (Studi Quasi Eksperiment Terhadap Peserta Didik SMAN 1 Jalancagak)

\author{
${ }^{1}$ Asep Deni Normansyah, ${ }^{2}$ Santi Nurhasanah \\ PPKn FKIP Universitas Pasundan \\ Alamat e-mail : asepdeninormansyah@unpas.ac.id
}

\begin{abstract}
This study uses a quasi-experimental method which aims to examine the influence of citizen project models in learning Pancasila education and citizenship on the development of civic competences of students. This research was carried out because of the still low development of civic competences for students. The problem under study is the improvement of students 'Civic Competences development skills and students' attitudes towards PPKn learning by using a project citizen model. Data analysis on the ability of Civic Competences development using independent sample t-test as well as attitude data analysis where attitude data uses a Likert scale. The results of the study show that: (1) improvement in the ability of Civic Competences development of students who obtain the Project Citizen learning model is better than students who use conventional learning models, which is seen from the analysis of the average gain in the experimental class that is 0.53 and the control class that is 0.40, (2) in general students are positive about learning PPKn by using the citizen project model which has an average of 3.43. The results of the study show that PPKn learning by using project citizen models can develop civic competences of students, thus the Project Citizen learning model can be used as an alternative for PPKn teachers in implementing PPKn learning in the classroom.
\end{abstract}

Keywords: Project Citizen Model, civic competences development, Conventional Model ABSTRAK

Penelitian ini menggunakan metode quasi eksperimen yang bertujuan untuk mengkaji pengaruh model project citizen dalam pembelajaran pendidikan pancasila dan kewarganegaraan terhadap pengembangan civic competences peserta didik. Penelitian ini dilaksanakan karena masih rendahnya pengembangan civic competences pada peserta didik. Masalah yang diteliti yaitu peningkatan kemampuan pengembangan Civic Competences peserta didik dan sikap peserta didik terhadap pembelajaran PPKn dengan menggunakan model project citizen. Analisis data kemampuan pengembangan Civic Competences menggunakan independent sample t-test begitu pula analisis data sikap dimana data sikap menggunakan skala likert. Hasil penelitian menunjukan bahwa: (1) peningkatan kemampuan pengembangan Civic Competences peserta didik yang memperoleh model pembelajaran Project Citizen lebih baik daripada peserta didik yang menggunakan model pembelajaran konvensional, yang dilihat dari analisis rata-rata gain pada kelas eksperimen yakni 0,53 dan kelas kontrol yakni 0,40, (2) pada umumnya peserta didik bersikap positif terhadap pembelajaran PPKn dengan menggunakan model project citizen yakni memiliki rata-rata 3,43 . Hasil penelitian menunjukan pembelajaran PPKn dengan menggunakan model project citizen dapat mengembangkan civic competences peserta didik, dengan demikian model pembelajaran Project Citizen dapat digunakan sebagai salah satu alternatif bagi guru PPKn dalam melaksanakan pembelajaran PPKn di kelas.

Kata Kunci : Model Project Citizen, pengembangan civic competences, Model Konvensional 


\section{PENDAHULUAN}

Pendidikan kewarganegaraan sangat penting dan memiliki esensi sebagai ujung tombak bagi suatu negara, maka hampir semua negara termasuk Indonesia memasukkan mata pelajaran Pendidikan kewarganegaraan ke dalam kurikulum pendidikan. Winataputra dan Budimansyah (2007) mengemukakan "Program pendidikan persekolahan mengemban misi untuk membentuk peserta didik agar kelak menjadi warga masyarakat sekaligus warga negara yang cerdas, terampil dan berwatak sebagai penjamin keberlangsungan bangsa dan negara”.

Peserta didik yang kapasitasnya sebagai "young citizen" atau warga negara muda yang merupakan ujung tombak untuk majunya pendidikan nasional dalam era globalisasi ini hendaknya mengembangkan kompetensi kewarganegaraan (civic competences), hal tersebut untuk memfilter segala perkembangan baik moral, gaya kehidupan, teknologi dan lain sebagianya. Namun dalam era globalisasi ini peserta didik yang diharapkan memiliki kualitas warga negara yang cerdas, kreatif, partisipatif, prospetif, dan bertanggung jawab kini mulai menghiraukan kompetensi kewarganegaraan (civic competences) yang memuat civic knowledge, civic skills dan civic dispotition, tidak adanya tanggung jawab moral, tidak memperdulikan kedisiplinan diri bahkan mulai tidak menghargai harkat martabat manusia dari setiap individu.

Realitanya, di Indonesia pembelajaran PPKn yang menekankan tentang penguasaan kompetensi kewarganegaraan masih terjadi ketimpangan, baik dalam struktur kurikulum maupun dalam pembelajaran di kelas. sehingga, mengingat betapa pentingnya civic competences yang meliputi pengetahuan kewarganegaraan (civic knowledge), keterampilan kewarganegaraan (civic skills), dan watak kewarganegaraan (civic disposition) dikembangkan bagi warga negara muda sebagai generasi penerus yang mendukung keberlangsungan masa depan bangsa, maka posisi pembelajaran Pendidikan Kewarganegaraan dalam mengajarkan pendidikan karakter serta mengembangkan kompetensi kewarganegaraan sangat strategis dalam membangun kepribadian peserta didik menjadi warga negara muda yang tidak hanya memiliki kecerdasan secara intelektual saja, namun juga memiliki good character citizenship seperti character privat dan character public.

Pembelajaran menggunakan project citizen diharapkan mampu meningkatkan tingkat partisipasi peserta didik dan keaktifan peserta didik di kelas. Dalam hal ini, dikarenakan proses pembelajaran project citizen mengajarkan peserta didik pembelajaran yang langsung berkaitan dengan konteks kehidupan sehari-hari. Model project citizen akan membantu peserta didik bukan hanya untuk memahami dimensi kognitif saja, tetapi juga mengembangkan kemampuan dimensi afektif dan psikomor untuk bekerja secara kooperatif dengan sesama peserta didik melalui kegiatan belajar praktik empirik dalam kelas.

\section{A. LANDASAN TEORI}

\section{Konsep Model Project Citizen}

Project Citizen merupakan model pembelajaran yang pertama kali di gunakan di California (USA) pada 1992 kemudian dikembangkan 
menjadi satu program nasional oleh Center for Civic Education (CCE) dan Konferensi Nasional Badan Pembuat Undang-Undang Negara pada tahun 1995 (Budimansyah, 2009, hlm. 1). Model ini telah diadaptasi menjadi model Praktik Belajar Kewarganegaraan yang diberi nama "Proyek-Belajar Kewarganegaraan: Kami Bangsa Indonesia" yang disingkat menjadi model "PKKBI" yang diujicobakan oleh Center for Indonesian Civic Education (CICED) bekerja sama dengan Center for Civic Education (CCE) dan Kanwil Depdiknas Jawa Barat. Project Citizen sendiri dikembangkan dari model pendekatan kritis atau reflektif yang dirintis oleh John Dewey dengan paradigma how we think.

Project Citizen adalah satu instructional treatment yang berbasis masalah untuk mengembangkan pengetahuan, kecakapan dan watak kewarganegaraan demokratis yang memungkinkan dan mendorong keikutsertaan dalam pemerintahan dan masyarakat sipil (civil society). Program ini mendorong para peserta didik untuk ikut aktif dalam organisasi pemerintah dan masyarakat sipil dalam memecahkan masalah di sekolah, masyarakat dan untuk mengasah kecerdasan sosial dan intelektual (Budimansyah, 2009, hlm. 1-2).

\section{Model pembelajaran Project} Citizen juga dikenal dengan portofolio based civic education project atau pembelajaran berbasis portofolio, yang dirancang dalam desain pembelajaran dimana memadukan secara sinergis modelmodel pemecahan masalah, penelitian sosial, perlibatan sosial, belajar kelompok, simulasi, dialog mendalam dan berpikir kritis serta kreatif, klarifikasi nilai, dan pembelajaran demokratis. Model Pembelajaran Berbasis Portofolio pada prinsipnya menggambarkan bahwa peserta didik membentuk atau membangun pengetahuannya melalui interaksinya dengan lingkungannya (Kamii, dalam Fajar, 2009, hlm. 43).

Budimansyah (2009, hlm. 33-

103) mengemukakan langkahlangkah model project citizen sebagai berikut:

a. Mengidentifikasi masalah kebijakan publik dalam masyarakat, pada tahap ini peserta didik diharapkan dapat berbagi informasi satu dengan yang lainnya berdasarkan pengetahuan yang sudah diketahui sebelumnya baik oleh peserta didik itu sendiri maupun dari orang lain berkaitan dengan permasalahan tersebut. Dengan demikian kelas memperoleh informasi yang cukup untuk digunakan memilih salah satu masalah yang tepat.

b. Memilih suatu masalah untuk dikaji oleh kelas, pada tahap ini kelas mendiskusikan semua informasi yang didapat berkenaan dengan daftar masalah yang ditemukan dalam masyarakat. Jika para peserta didik telah memiliki informasi yang cukup, maka peserta didik sudah dapat memilih masalah yang akan dipilih sebagai materi kajian kelas.

c. Mengumpulkan informasi yang terkait pada masalah itu, maslah yang akan menjadi materi kelas ditentukan, maka para peserta didik harus bisa memutuskan tempat-tempat atau sumbersumber dimana peserta didik bisa mendapat informasi tambahan. Dalam pencarian informasi, 
nantinya para peserta didik akan menemukan bahwa sumber informasi yang satu mungkin lebih baik dari yang lainnya, hal ini mungkin saja terjadi agar kelas dapat memperoleh informasi yang akurat dan komprehensif.

d. Mengembangkan project citizen kelas, pada tahap ini peserta didik akan dibagi dalam empat kelompok, dimana masingmasing kelompok akan bertanggung jawab untuk mengembangkan project citizen kelompok. Materi-materi yang dimasukan dalam project citizen hendaknya mencakup dokumentasi-dokumentasi yang telah dikumpulkan dalam tahap penelitian masalah. Dalam mengembangkan project citizen ini sangat dibutuhkan kerjasama yang baik agar menghasilkan tayangan dan dokumentasi yang baik dan bagus sebagai materi kajian showcase nantinya. Kelompok pertama menjelaskan tentang masalah yang diambil, Kelompok kedua mengkaji kebijakan alternatif untuk menangani masalah, Kelompok ketiga mengusulkan kebijakan alternatif untuk menangani masalah, dan Kelompok keempat mengembangkan rencana kerja dari kelompok untuk menyelesaikan masalah.

e. Menyajikan project citizen, langkah berikutnya adalah menyajikan hasil pekerjaan dihadapan para juri. Presentasi tersebut dikenal dengan sebutan showcase yang dilakukan dihadapan dewan juri yang mewakili sekolah dan masyarakat. Melalui kegiatan ini para peserta didik akan dibekali dengan pengalaman belajar bagaimana cara meyakinkan mereka terhadap langkahlangkah yang peserta didik ambil.

f. Melakukan refleksi pengalaman belajar,merefleksikan pengalaman belajar atas segala sesuatu selalu merupakan hal yang baik, refleksi pengalaman belajar ini merupakan salah satu cara belajar, untuk menghindari agar jangan sampai melakukan suatu kesalaha, dan untuk meningkatkan kemampuan yang sudah peserta didik miliki.

\section{Konsep Civic Competences}

Kompetensi kewarganegaraan (civic competences) merupakan kemampuan yang harus dikuasai seorang peserta didik yang meliputi pengetahuan, nilai dan sikap, serta keterampilan peserta didik yang mendukungnya menjadi warga negara yang partisipatif dan bertanggung jawab dalam kehidupan bermasyarakat, berbangsa dan bernegara (Susanto, 2014, hlm. 5).

Dari uraian tersebut maka kompetensi warga negara (civic competence) terbagi menjadi pengetahuan kewarganegaraan (civic knowledge), kecakapan kewarganegaraan (civic skills), dan sikap/watak kewarganegaraan (civic disposition) yang sangat berguna dan bermanfaat bagi kehidupan seorang warga negara khususnya untuk peserta didik yang memiliki kapasitas sebagai warga negara muda yang mendukungnya menjadi warga negara yang partisipatif dan bertanggung jawab dalam kehidupan bermasyarakat, berbangsa dan bernegara

Dimensi-dimensi civic competences yakni pengetahuan kewarganegaraan (civic knowledge), kecakapan kewarganegaraan (civic 
skills), dan sikap/watak kewarganegaraan (civic disposition).

Pengetahuan kewarganegaraan (civic knowledge) merupakan materi substansi yang harus diketahui oleh warga negara. Pada prinsipnya pengetahuan yang harus diketahui oleh warga negara berkaitan dengan hak dan kewajiban sebagai warga negara. Selain itu, pengetahuan kewarganegaraan (civic knowledge) berkaitan dengan kandungan atau apa yang seharusnya diketahui oleh warga negara yang memicu untuk berpikir kritis dan memicu untuk bertindak menjadi warga negara yang baik dan cerdas.

\section{Keterampilan}

Kewarganegaraan (Civic Skills) merupakan keterampilan yang dikembangkan dari pengetahuan kewarganegaraan, agar pengetahuan yang diperoleh menjadi sesuatu yang bermakna, karena dapat dimanfaatkan dalam menghadapi masalah-masalah kehidupan berbangsa dan bernegara. Civic Skills mencakup intelectual skills (keterampilan intelektual) dan participation skills (keterampilan partisipasi).

Dimensi civic skills ini dikembangkan dengan tujuan untuk memberikan pengetahuan dan keterampilan yang diperlukan untuk berperan serta secara efektif dalam masyarakat, pengalaman berperan serta yang dirancang untuk memperkuat kesadaran berkemampuan dan berprestasi unggul dari peserta didik, dan mengembangkan pengertian tentang pentingnya peran serta aktif warga negara.

Watak kewarganegaraan (civic disposition) merupakan sikap, kebiasaan, karakter, atau watak warga negara dalam menopang berkembangnya fungsi sosial yang sehat dan jaminan atas kepentingan umum dalam sistem demokrasi yang merujuk kepada karakter privat dan karakter publik serta merupakan bagian dari civic virtue (kebajikan kewarganegaraan) yang terdiri atas unsur watak dan komitment kewarganegaraan.

\section{METODE PENELITIAN}

Metode yang digunakan dalam penelitian ini adalah metode kuasi ekperimen. Dalam hal ini variabel bebasnya adalah model Project Citizen dan variabel terikatnya adalah pengembangan civic competences peserta didik. Penelitian yang digunakan dalam penelitian ini adalah desain kelompok kontrol pretespostes (pretest-posttest control grup design) yang melibatkan dua kelompok dan dipilih secara random. Dengan desain ini sampel dibagi dalam 2 kelompok yaitu satu kelompok dengan eksperimen dan satu kelompok lagi dengan kelompok kontrol.

Perlakuan dalam penelitian ini adalah pembelajaran pada kelompok eksperimen menggunakan model project citizen dan pada kelompok kontrol menggunakan model pembelajaran konvensional. Kelompok eksperimen dan kelompok kontrol mendapatkan soal pretest dan posttest yang sama untuk melihat pengembangan civic competences peserta didik. Populasi dalam penelitian ini adalah seluruh peserta didik kelas XI SMA Negeri 1 Jalancagak Kabupaten Subang. Dan sampel penelitianya yaitu kelas XI yang diambil secara acak dari sembilan kelas yang ada di kelas XI SMA Negeri 1 Jalancagak. Adapun kelas yang terpilih adalah kelas XI MIPA-1 sebagai kelas eksperimen dengan menggunakan model 
pembelajaran project citizen, dan kelas XI MIPA-2 sebagai kelas kontrol dengan menggunakan model pembelajaran konvensional.

\section{HASIL PEMBAHASAN}

Setelah dilakukan pengolahan hasil penelitian pada kelas eksperimen dan kelas kontrol, maka diperoleh hasil sebagai beriku:

Tabel 1.1 Perbandingan hasil rata-rata nilai pretest-posttest pada kelas ekperimen dan kelas kontrol

\begin{tabular}{|c|c|c|c|}
\hline Kelas & Pretest & Posttest & $\begin{array}{c}\text { Pening } \\
\text {-katan }\end{array}$ \\
\hline $\begin{array}{c}\text { Eksperi } \\
\text {-men }\end{array}$ & $36 \%$ & $71 \%$ & $35 \%$ \\
\hline Kontrol & $37 \%$ & $64 \%$ & $27 \%$ \\
\hline
\end{tabular}

Dari hasil tersebut terlihat bahwa pada kelas eksperimen nilai rata-rata peserta didik sebelum mendapatkan perlakuan pembelajaran menggunakan model project citizen yakni 36\%. Namun setelah mendapatkan perlakuan pembelajaran dengan menggunakan model project citizen nilai rata-rata peserta didik menjadi $71 \%$. Dari hasil tersebut pada kelas eksperimen hasil rata-rata peserta didik meningkat $35 \%$.

Sedangkan pada kelas kontrol hasil rata-rata peserta didik pada saat pretest yakni $37 \%$. Setelah mendapatkan perlakuan pembelajaran dengan menggunakan model konvensional hasil rata-rata peserta didik menjadi 64\%. Dari hasil tersebut pada kelas kontrol hasil ratarata peserta didik hanya meningkat $27 \%$.
Tabel 1.2 Diagram hasil gain pada kelas eksperimen dan kelas kontrol

Pengembangan Civic Competences

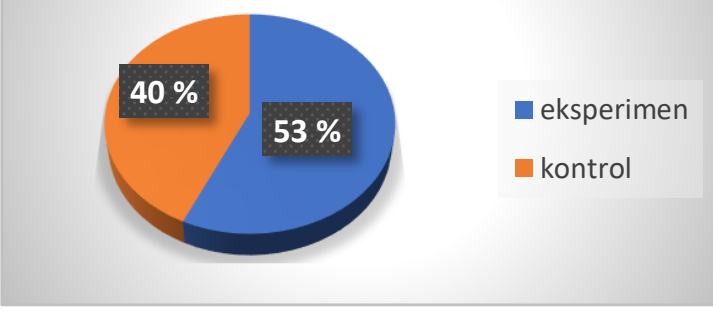

Sejalan dengan hasil rata-rata nilai pretest-posttest peserta didik pada kelas ekperimen dan kelas kontrol yang mengalami peningkatan, hal tersebut didukung oleh hasil gain yang menyatakan bahwa pada kelas eksperimen memperoleh hasil gain $53 \%$ dan $40 \%$ untuk kelas kontrol.

Dari data tersebut dapat disimpulkan bahwa peningkatan pengembangan civic competences kelas eksperimen yang mendapatkan perlakuan pembelajaran dengan menggunakan model project citizen lebih baik dari pada pengembangan civic competences kelas kontrol yang mendapatkan perlakuan pembelajaran dengan menggunakan model konvensional.

Selain dilihat dari hasil pretestposttest, untuk mengetahui pengaruh model pembelajaran project citizen terhadap pengembangan civic competences peserta didik, peneliti menggunakan angket skala likert. Angket diberikan hanya kepada peserta didik pada kelas eksperimen, hal tersebut untuk mengetahui sikap peserta didik terhadap pengembangan civic competences dan model pembelajaran project citizen. 
Tabel 1.3 Hasil rata-rata angket pada kelas ekperimen

\begin{tabular}{|c|c|}
\hline Kelas & $\begin{array}{c}\text { Hasil Rata-Rata } \\
\text { Angket }\end{array}$ \\
\hline Eksperimen & 3,43 \\
\hline
\end{tabular}

Berdasarkan tabel 1.3 dapat dilihat rata-rata sikap peserta didik terhadap pembelajaran PPKn menggunakan model project citizen dan terhadap pengembangan civic competences peserta didik adalah 3,43 . Menurut Suherman dan Sukjaya (dalam Hernita, 2015, hlm. 41), "jika nilai perhitungan skor rata-rata lebih dari 3 artinya respon peserta didik positif dan bila nilai perhitungan skor rata-rata kurang dari 3 artinya respon peserta didik negatif'. Karena 3,43 > 3,00 maka dapat disimpulkan bahwa sikap peserta didik positif terhadap pembelajaran PPKn menggunakan model project citizen, dan terhadap pengembangan civic competences peserta didik.

\section{KESIMPULAN}

Berdasarkan penelitian yang dilaksanakan mengenai pengaruh model pembelajaran project citizen dalam pembelajaran pendidikan pancasila dan kewarganageragaan terhadap pengembangan civic competences peserta didik di SMA Negeri 1 Jalancagak diperoleh kesimpulan sebagai berikut:

1. Peningkatan pengembangan civic competences peserta didik yang memperoleh model project citizen lebih baik daripada peserta didik yang memperoleh model pembelajaran konvensional.

2. Dengan adanya pembelajaran PPKn dengan menggunakan model project citizen peserta didik menujukan sikap positip terhadap pembelajaran PPKn dan pengembangan civic competences.

3. Adanya pengaruh model project citizen dalam pembelajaran PPKn terhadap pengembangan civic competences peserta didik dibandingkan dengan menggunakan model pembelajaran konvensional.

\section{DAFTAR PUSTAKA}

Budimansyah. (2009). Inovasi Pembelajaran Project Citizen. Bandung: Sekolah Pascasarjana Universitas Pendidikan Indonesia

Fajar, Arnie. (2009). Portofolio Dalam Pembelajaran IPS. Bandung: PT Remaja Rosdakarya.

Hernita, Agustriyani. (2015). Pengaruh Penerapan Model Eliciting Activities (MEAs) Terhadap Peningkatan Kemampuan Berpikir Kreatif Matematic Siswa SMP. Skripsi Pendidikan Matematika, FKIP Unpas: Tidak Diterbitkan.

Winataputra, \& Budimansyah. (2007). Civic Education : Konteks, Landasan, Bahan Ajar, Dan Kultur Kelas. Bandung: Sekolah Pascasarjana Universitas Pendidikan Indonesia 